\title{
Factors Impacting on CMMI Acceptance Among Software Development Firms: A Qualitative Assessment
}

\author{
Hamad Alsawalqah ${ }^{1}$, Yazan Alshamaileh ${ }^{1}$, Bashar Al-Shboul ${ }^{1}$, Areej Shorman ${ }^{1}$ \& Azzam Sleit ${ }^{1}$ \\ ${ }^{1}$ King Abdullah II School of Information Technology, The University of Jordan, Amman, Jordan \\ Correspondence: Yazan Alshamaileh, King Abdullah II School of Information Technology, The University of \\ Jordan, Amman 11942, Jordan. E-mail: y.shamaileh@ju.edu.jo
}

Received: December 30, 2018

Accepted: January 11, 2019

Online Published: February 28, 2019

doi:10.5539/mas.v13n3p170

URL: https://doi.org/10.5539/mas.v13n3p170

\begin{abstract}
Productive firms try to deliver high-quality products to be globally competitive. Therefore, software development firms need to adhere to a set of best practices that improve their processes. Capability maturity model integration (CMMI) comprehensively assesses the maturity of a firm's processes. Representing a major departure from the traditional method of running quality management in software development firms, the adoption of CMMI has major ramifications and long-lasting effects on a company's quality procedures. Unfortunately, the literature lacks information as to how firms should implement CMMI. Our research involved conducting an exploratory study examining the major factors that influenced CMMI adoption for Jordanian software development firms. Quality managers from eighteen software development organizations took an open-ended survey. The results show that the main factors in CMMI implementation in Jordanian software development firms were issues of its being too costly, having no time, dealing with market scope, and lack of top management support. Conclusions are also presented.
\end{abstract}

Keywords: Capability Maturity Model Integration (CMMI), Medium-to-Small Sized Enterprises (SMEs), Software Process Improvement (SPI)

\section{Introduction}

As software continues to intertwine with all aspects of our lives, we must pay more attention to the quality of software in both academia and industry. The issue of software quality has been brought into sharp focus because of the disappointing performance of some high-profile software projects and the high rate of software project failure (Sommerville, 2011). Generally, there are two main ways to evaluate the quality of software. The first is to assess the quality of the software after producing it by measuring non-functional requirements such as usability, reliability, and ease of learning. These describe the properties of software as a whole. The second way is to assess the quality of software by determining whether the steps of the process used to produce the software are correct. The search for ways to improve software quality has continued for many years, and software organizations have realized that one of their fundamental problems is the inability to effectively manage software processes (Butler, 1995; Pitterman, 2000; Yamamura, 1999). To attain the effective management of software processes, different software process improvement (SPI) standards have been developed. SPI is a long-standing approach to help organizations develop higher quality software more efficiently (Staples et al., 2007).

Capability maturity model integration (CMMI) is a SPI framework that focuses on processes to achieve quality software (Niazi, Babar \& Verner, 2010; Niazi, Wilson \& Zowghi, 2006). CMMI is defined as a process improvement maturity model administered and marketed by Carnegie Mellon University (CMU) for the development of products and services (Beynon, 2007). The main objective of this model is to reduce the cost of implementing improvements to an organization's processes by eliminating inconsistencies and to establish guidelines to assist the organization at different stages of a software project (Silva et al., 2015). According to the CMMI Institute (2018), there are over 10,000 organizations and businesses that use CMMI models from over 101 countries, including the United States, Russia, China, Australia, and Germany. Moreover, 11 governments invest in CMMI to support economic development in their countries (Nath, 2016). CMMI models have been translated into ten languages to support governments and organizations. The CMMI certificate was developed by the Software Engineering Institute of Carnegie Mellon University and consists of five levels of maturity for an organization. The levels are designed to improve the processes of software companies and discover the strengths 
and weaknesses of their existing processes (Pusatli \& Misra, 2011). Pusatli and Misra stated that the CMMI certificate is considered one of the highest standards in the software industry. A number of performance results supporting the benefits of CMMI have been reported in the literature, such as reductions in cost and improvements in productivity, work schedule, and work quality (Chrissis, Konrad \& Shrum, 2003; Khan \& Keung, 2016; Kishore, Swinarski, Jackson \& Rao, 2012).

Oxford Business Group (2015) stated that Jordan was one of the first Arabic countries to introduce communication and information technology into the economy. However, over the last decade, Jordan has been overtaken by regional economies for many reasons. One main reason is the country's lack of awareness about the adoption of SPI standards. These standards introduce different quality management methodologies to the software industry that assure the delivery of high-quality software and increase customer satisfaction (Rainer \& Hall, 2002). Unfortunately, many Jordanian IT companies do not apply SPI standards (e.g., CMMI) in all phases of the software life cycle (Abdali \& Mohammad, 2005). An empirical study investigated the use of CMMI in web development companies and found that the majority of the respondents (81\%) had not previously participated in any SPI activities such as training, implementation, and practicing (Al-Allaf, 2012). Consequently, many Jordanian IT companies suffer from serious problems such as missed commitments, late deliveries to the market, inadequate management capabilities, quality problems, and inadequate control of project results, which, in turn, lead to too much rework (Abu-Baker, 2012). Adopting CMMI might facilitate increased cooperation among ICT companies and improve Jordan's capability to develop internationally sustainable national ICT competitiveness (Abu-Baker, 2012).

In general, recent data about CMMI adoption in Jordan are limited. In Jordan, most firms do not know how to apply or use CMMI. As a result, firms avoid using such models. A fundamental challenge for decision makers is determining whether to adopt CMMI. Identifying and understanding the key factors that influence the decision to adopt CMMI marks the starting point of approaching this challenge. To tackle this problem, we conducted an exploratory research to investigate the factors influencing CMMI adoption in Jordanian software development firms. The objective of this paper is to study these factors. Hence, in this study we will address the following research question: What factors identified by Jordanian software firms have the greatest impact on CMMI adoption in Jordan?

The rest of this paper is organized as follows. Section 2 presents the important factors in adopting CMMI in the literature. Section 3 describes the research methodology. Section 4 presents the findings and discussion. Section 5 provides the conclusion.

\section{Related Work}

CMMI was developed by integrating many different maturity models into one framework to guide the improvement of processes across a project, division, or organization (Khan, Keung, Niazi, Hussain \& Ahmad, 2017; Khan \& Khan, 2013; Niazi et al., 2006, 2010). Several empirical studies have investigated factors that positively or negatively affect SPI (Abdali \& Mohammad, 2005; Dybå, 2003; Kouzari, Gerogiannis, Stamelos \& Kakarontzas, 2015; Silva et al., 2105). Magdaleno, Werner, and De Araujo (2012) identified that the problem with the existing SPI was not the lack of a standard or model to follow, but rather the lack of an effective strategy to successfully implement these standards or models.

In the last decade, a variety of research projects have studied the factors associated with the decisions firms make to adopt SPI models (e.g., Abdali \& Mohammad, 2005; O'Connor \& Coleman, 2007; Dybå, 2003; Kouzari et al., 2015; Niazi, 2015; Silva et al., 2015; Wongsai, Siddoo, \& Wetprasit, 2015; ). Staples and Niazi (2008) systematically reviewed almost 600 papers related to CMMI and found that among these no studies addressed why organizations decide not to adopt process capability maturity SPI. Niazi (2015) was the first to report an empirical study of reasons why software developing organizations do not adopt CMMI. The most frequent reasons were that the service was too costly, the organization was using another SPI approach, and the organization had no time. After replicating the study in another country, Wongsai et al. (2015) suggested that researchers need to develop a stronger cost-benefit analysis for SPI and recognize it as a business investment rather than just a product or process quality improvement technique.

Almost three questers of Goldenson and Herbsleb's (1995) respondents reported that "process improvement has often suffered due to time and resource limitations;" over three quarters also said that process improvement had taken longer than they expected, and over two-thirds said it cost more than they expected. Some cross-sectional studies have suggested an association between cost and the adoption of SPI models like CMMI (e.g., Staples et al., 2007). Certainly, the implementation of CMMI will increase cost overheads, especially when it is applied in small firms with smaller economies of scale and limited resources or funds (Staples et al., 2007). O'Connor 
and Coleman's (2007) field study found that many software managers rejected SPI because of the associated implementation costs; they were reluctant to implement SPI models such as ISO 9000 and CMMI. A number of studies has found that time limitation is essential to firms' decisions to adopt a new SPI (Niazi, 2009; Niazi et al., 2006, 2010). Time has been considered a pressure factor in SPI implementation that may affect team members' decisions and ability to deliver products on schedule (Khan \& Keung, 2016; Khan et al., 2017). For instance, Staples et al. (2007) found that time was the most important influence on the adoption of CMMI in small firms in Australia. These firms had limited available time, which hindered their implementation of services offered by CMMI and therefore their access to its benefits. Consequently, this factor has been said to have an impact on SPI adoption because most small firms consider that involvement in most SPI activations is time consuming and too costly (Staples et al., 2007). Different research project initiations have emerged to meet SPI adoption challenges related to cost and time limitations among Medium-to-Small Sized Enterprises (SMEs). Villalón et al. (2002) attempted to establish a fine approach called MESOPYME (Note 1) to reduce the overhead in time and cost upon adopting SPI. This method provided a solution via a set of components to problems that may appear in software development in SMEs. This approach uses the concept of an action package, a group of firms providing solutions to problems that may appear in the development process (Villalón et al., 2002).

The literature (Conradi \& Fuggetta, 2002; El Emam \& Koru, 2008; Khan \& Keung, 2016; Khan \& Khan (2013); Kouzari et al., 2015; Niazi et al., 2006; Sulayman et al., 2014; Rainer \& Hall, 2002; Ramasubbu, 2014) has shown that top management support is a key factor for SPI implementation primarily because good management helps decision-making when adopting new technologies and processes, thus it helps to improve the quality (Kouzari et al., 2015). In addition, the high involvement of the management team increases chances of successful projects through the efficient use of resources. Commonly, this kind of support is needed to maintain the importance of possible change through an articulated vision for the firm and by emphasizing the importance of the next step of development to working teams in the organization (Khan \& Keung, 2016; Niazi et al., 2006; Rainer \& Hall, 2002).

Market scope refers to the horizontal extent of a company's operations (Zhu et al., 2003). SMEs typically operate locally, but they sometimes operate nationally and even internationally. To span the geographically dispersed units of the organization, SMEs are required to have a systematic, mechanistic, good reputation in developing software. This forces firms to adopt more efficient and streamlined models and avoid ad hoc procedures in software development projects (Zhu et al., 2003). Existing SPI models can be used to remove the potential demand conflicts with clients in different geographic regions. Hens the existence of international software development process standards which made software development firms in need of a uniform model addressing different types of software projects (Khandelwal \& Ferguson, 1999).

CMMI promises a variety of benefits for the companies adopting it. According to Kouzari et al. (2015), CMMI can offer many advantages related to efforts, software management, performance, and quality. In fact, choosing a better SPI model may help businesses offer lower prices, thus being able to increase their market advantage. International Software Development Process Standards can be used by small firms to reach this goal. Chopra and Meindl (2007) demonstrated that when firms expand their market reach, they incur inventory holding costs and possible search costs (e.g., searching for consumers, trading partners, and distributors). SMEs adopting SPI services are expected to be less location dependent and to handle the requirements of different clients from different backgrounds and countries.

By reviewing and analyzing the literature, we describe the most studied factors that affected firms' decisions to adopt SPI models in Table 1. Describing the factors provides the reader with knowledge about the strengths and weaknesses that affect a firm's decision to adopt CMMI.

\section{Methodology}

This research aims to study the factors that affect CMMI adoption. The main objective is to study the CMMI adoption process by software development companies in Jordan. More specifically, we aim to investigate which factors are likely to influence the decision to adopt CMMI and to what extent does each factor affect the decision making process. We considered a qualitative study appropriate for this exploratory work because it enabled a deeper analysis of the underlying factors. With the purpose of exploring the impact of a list of factors for SMEs adopting CMMI, we deemed empirical work using open-ended survey questions appropriate as the data collection method. Open-ended surveys are a form of qualitative research to collect qualitative data. Mostly, they take the form of a text box in a survey software called SurveyMonkey (2017). This type of data collection has been used in a number of studies. As a part of collecting research data, the researchers Bartsch, Roberts, Davies, and Proeve (2015) used the qualitative interview format and open-ended responses to answer their research 
questions. The research acknowledges the privileges of employing this type of data collection that provides the flexibility to gather and summarize a broad range of clinical observations. This approach gives respondents the freedom to say exactly what they feel about a topic, which provides exploratory data that may reveal unforeseen opportunities, issues, or quotes (Farrell, 2016). In this research project, an online open-ended survey was developed to extract the opinions of the respondents and to ascertain which factors have an impact on the decision to adopt CMMI among software development companies.

Table 1. Factors identified in the literature as influencers of SPI adoption

\begin{tabular}{ll}
\hline Factor Name & Factor Description \\
\hline Complexity & The degree to which CMMI is perceived as relatively difficult to understand and \\
implement. & The consideration that implementing CMMI will increase cost overheads \\
Costliness & considering the resources and funds. According to Staples et al. (2007), small \\
& organizations avoid adopting CMMI models because they face other obstacles. \\
& Villalón et al. (2002) state that small- and medium-sized enterprises confirm that \\
& applying SPI models costs a lot. \\
Top & Top management support helping to focus efforts toward spreading awareness of \\
Management & the organizational benefits of adopting CMMI and lending credibility to the \\
Support & implementation. In his study, Niazi (2015) found that in the three strategies; \\
& informal literature review, SLR, and interviews, top management is a key factor \\
for a successful adaptation to any SPI model. \\
Staff
\end{tabular}$\quad \begin{aligned} & \text { The extent to which employees use their knowledge and experience to decide, } \\
& \text { act, and take responsibility in CMMI implementation. Khan et al. (2009) } \\
& \text { conducted a systematic literature review to investigate the success factors of } \\
& \text { selecting software and outsourcing vendors across three continents. They found } \\
& \text { that the percentage of experienced employees as a success factor is a high 67\%. } \\
& \text { This indicates that having an experienced, skilled staff influences the selection. }\end{aligned}$

Time

Restrictions

Negative Prior

Experience

Concern for

Measurement

Innovativeness

Firm Image

Using Other SPI

Firms have a length of time to use the services presented by CMMI and to reap the benefits. Staples et al. (2007) state that time controls the implementation process. Conradi and Fuggetta (2002) confirmed that applying SPI frameworks such as CMM is considered time- consuming. It takes four to five years to move from Level 1 to Level 3 in the implementation of a CMM while most companies have less than twelve months to improve.

Bad examples and case studies influence the adoption of CMMI.

The extent to which the software organization collects and uses quality data to guide and assess the effects of SPI activities is a concern.

Innovativeness (the extent to which the software organization is engaged in exploring new knowledge and adopting innovations earlier than other members of the same social environment). Software organizations are concerned about quality software. As a result, they try to adopt new quality models such as CMMI in order to save time and money as well as provide high quality products. Researches showed that firms that adopt SPI models such as CMMI have a better image than those who do not through the quality of the produced software.

Firm is already using other SPI models.

Market Scope The horizontal extent of a company's gain and recognition.

\section{References}

Ifinedo, 2011

Staples et al., 2007; Kouzari et al., 2015; Villalón et al., 2002

Niazi, 2015; Khan et al., 2017; Wang, Y.-M., Wang, Y.-S., Yang, Y.-F., 2010

Niazi, 2015; Kouzari et al., 2015; Khan et al., 2009; Sulayman, Mendes, Urquhart, Riaz \& Tempero, 2014; El Emam \& Koru, 2008; Rainer \& Hall, 2002.

Staples et al., 2007; Khan et al., 2017; Ramasubbu, 2014; Conradi \& Fuggetta, 2002

Niazi et al., 2010; Ifinedo, 2011

Niazi et al., 2006

Niazi et al., 2006

Niazi et al., 2006

Brietzke \& Rabelo, 2006; Silva et al., 2015

Zhu, Kraemer \& Xu, 2003; Khandelwal \& Ferguson, 1999

We first conducted a pilot study with two firms to verify whether the questions were clear in their intent and meaning. After the instrument was tested, we revised, reformatted, and placed it on a website. The final 
web-based survey consisted of the following statements:

1) Please review the following factors, then select the top five factors that influence your firm's decision to adopt a SPI such as CMMI.

2) Please provide comments about each factor you have chosen.

3) What is your firm's size (number of employees)?

4) Does your company use CMMI? If so, which level?

The first question sought to highlight the top factors that firms take in consideration regarding CMMI adoption in their company. The second question sought to understand firms' perspectives regarding different factors they deem important. In addition to the main questions, demographic information was also obtained from respondents. Respondents completed and submitted the survey online. Some respondents responded in Arabic and some in English. Arabic answers were translated into English. Additionally, data were gathered from secondary sources such as internal company documentation and firm websites. This research project examined 18 SMEs located in the Hashemite Kingdom of Jordan. This is a convenient rather than a random sample of SMEs (Table 2). The target population in this study was small- or medium-sized Jordanian software firms. Almost half of the firms had fewer than 10 employees, and the remainder had between 10-250 employees. Only one firm had already applied for a CMMI certificate (Level 3).

\section{Findings and Discussion}

Table 3 presents a list of factors related to CMMI adoption reported by Jordanian software development firms. These results show that our respondents considered the following to be key factors in their decision-making process: being too costly, having no time, unclear market scope, and lacking top management support.

Too costly: Of the firms, $72.22 \%(13 / 18)$ stated that cost was a main factor they considered for CMMI adoption. Cost was considered the main factor in adopting any model or technology. Most small software development firms in Jordan cannot afford the successful, official implementation of a SPI framework as a result of the financial requirements and difficulties associated with the experience. Software Firm (SF) 8 noted, "Cost is the major factor in any decision when the company is micro-scale.". SMEs usually have a limited budget, and all their expenses must be strictly justified (O’Connor \& Coleman, 2007). SF2 highlighted the importance of cost saying, "Every penny a company plans to spend is usually studied for its ROI. In this case, CMMI cost will have to be justified as an investment." Implementing and maintaining any SPI initiative incurs a significant cost. This is clearly reflected by SF14, who wrote, "The cost of adherence and certification is high," and by SF13, who wrote that the "cost of moving from Level 0 to Level 2 is huge." Applying for CMMI certification is relatively demanding: "It takes time and resources to achieve the credentials, and we do not have a lot of both to spare" (SF11). In general, most participants concluded that cost plays a key role in their decision to adoption CMMI. SF16 stated, "Cost is the main reason."

No Time: This research strongly confirmed the findings in the literature review that time is one of the main factors considered for CMMI adoption. Of the sample selected, $61.11 \%(11 / 18)$ commented that this was an important factor. The IT managers were concerned that time is closely related to the previous factor (cost) as mentioned by SF8, "Time is money, and cost is the factor," and SF18, who wrote, "It might be an issue if it requires extra cost." Most projects in Jordanian software development firms have a short life span, so they do not need a sophisticated methodology to follow. This is clearly pointed out in SF17's answer that "Some requirements need one or two weeks, so there is no need for a sophisticated methodology to follow from A-Z until meeting the customer's requirement. In this case, the complexity is reduced."

Market Scope: This research showed that market scope is one of the main factors considered for CMMI adoption. Of the sample, 55\% (10/18) commented that this was an important factor. Some of the firms highlighted that the nature of their operations will be affected when choosing a suitable SPI model to apply. "Working in specific domains such as banking or government may affect the decision of adopting CMMI" (SF18). Most software firms in Jordan are SMEs and operate locally, but if the firms want to expand their market internationally, they want to adopt SPI models like CMMI. This is clearly reflected in the answer by SF11, "If we expand our target audience to bigger firms and to other markets, then we might consider CMMI or another SPI, if, and only if, it adds value." SF8 wrote, "We are not targeting large scale customers who require a certain standard in internal processes," and SF12 noted, "Sometimes the market demands a certain level of accreditation in order to be eligible to participate in the projects/tenders." 
Table 2. Jordanian software firms (SFs), their size, and their adoption of CMMI

\begin{tabular}{lll}
\hline Firm No. & Size (1-9/10-250) & Using CMMI (YES/NO) \\
\hline SF1, SF2, SF3, SF4, SF5, SF8, SF11, SF12, SF13, SF16 & $1-9$ & No \\
SF6, SF9, SF10, SF14, SF15, SF17, SF18 & $10-250$ & No \\
SF7 & $10-250$ & Yes \\
\hline
\end{tabular}

Table 3. The factors most affecting CMMI adoption in Jordanian software firms

\begin{tabular}{lll}
\hline Factors & Frequency Factor & Frequency Percentage \\
\hline Too Costly & 13 & $72.22 \%$ \\
No Time & 11 & $61.11 \%$ \\
Market Scope & 10 & $55.55 \%$ \\
Top Management Support & 9 & $50.00 \%$ \\
\hline
\end{tabular}

Regarding the market scope, it is apparent from the results that business needs will influence the decision to adopt CMMI. "Whenever the market scope of a firm is extended, it will be mechanistic. This means it needs more control and a clear methodology like CMMI," (SF17).

Top Management Support: This is an old theme that was identified in the literature as a strong factor affecting the decision to adopt CMMI (Conradi \& Fuggetta, 2002; El Emam \& Koru, 2008; Khan \& Keung, 2016; Khan \& Khan, 2013; Kouzari et al. 2015; Niazi et al., 2006; Rainer \& Hall, 2002; Sulayman et al., 2014). Of the sample, $50 \%(9 / 18)$ found that top management support was a significant factor when considering the adoption of CMMI. Said SF17, “Top management support is a very important factor because the support helps focus efforts toward the creation of awareness of the organizational benefits of adopting CMMI and lends credibility to the implementation." This is mainly because higher management support in Jordanian software development firms helps guarantee good results and improves reputation. This is clearly expressed in the answers given by SF11, "We have a SPI in place, and showcasing this in our presentations to clients briefly reflects a better professional image," and by SF12, "This is a good factor especially if the targeted market has high maturity in selecting their software vendors," such as when dealing with the ITC sector in the gulf, Europe, or the United States. We found that without top management support the firms are less likely to adopt new SPI models. SF8 stated that "top management support will take the necessary actions to speed up the process of SPI model adoption," whereas SF7 explained that "if we have top management support, we can adopt any SPI model." In addition, less management support means that not every step of the process is tailored to the business goals, and there may not be control over using resources efficiently. As SF13 said, there is a "lack of top management awareness of CMMI in Jordan."

These findings have important implications for the adoption rates of different SPIs in software development firms in Jordan. It is important to understand why software development firms hesitate to adopt SPI frameworks such as CMMI. Most software development companies in Jordan and other countries still lack a deep understanding of CMMI. This means that there is not enough knowledge about successful strategies for CMMI adoption among potential adopters. In fact, according to this research project's findings, the main stereotype about CMMI is that it is too costly. This means that most software development firms in Jordan are not even considering CMMI as an appropriate SPI framework for their software process improvement. It is important to raise awareness among software development firms' managers of process improvement values when their firms are adopting CMMI or planning to do so. Being aware of the key relationships that exist among CMMI process areas will assist managers in implementing CMMI in an effective and useful way. It is important for the managers of firms to try learning more about how to calculate the return on investment (ROI) of CMMI-based efforts. Reducing firm costs could make CMMI a cost-effective option for many software development organizations.

\section{Conclusion}

To have better methods of developing and evaluating software and so succeed in the market, firms must deliver high-quality software and related services, such as technological support and communication with customers (Horvat, Rozman, \& Györkös, 2000). SPI is a powerful method that aims to support organizations in developing higher quality software (Staples et al., 2007). CMMI is one of the main SPI frameworks that define and measure processes and practices. All organizations, despite their size, should aim to achieve the highest quality of products and services (Horvat et al., 2000). However, there are several factors that weaken the SPI initiative. 
Staples et al. (2007) found that the implementation of models such as CMMI can be difficult because of resource constraints and the knowledge needed to design and develop CMMI practices. Niazi (2015) is in favor that "to benefit from Software Process Improvement, organizations should pledge resources in an extensive period of time. On the other hand, small- and medium-sized organizations have their own concerns about the effectiveness of some SPI models". This exploratory study focused on the factors influencing CMMI adoption in Jordanian software development firms using open-ended survey questions to collect data. The results of this research will be useful in both academia and professional fields to help firms to reformulate their strategies according to the most important factors affecting CMMI adoption in Jordan. In addition, the results serve to provide SPI managers with a body of knowledge that can help them adopt CMMI by honing in on a limited number of factors affecting adoption.

\section{Acknowledgment}

This work was supported by the Deanship of Academic Research, The University of Jordan.

\section{References}

Abdali, R. A., \& Mohammad, O. (2005). Software industry in Jordan the Prospects and Hopes. In The 2nd International Conference (pp. 3-5).

Abu-Baker, M. I. (2012). The Effect of the Implementation of CMMI at Achieving End Users Satisfaction Analytical Study on Soft Ware Companies at Hashemite Kingdom of Jordan. Al-Balqa' Applied University, Jordan.

Al-Allaf, O. N. (2012). The usage of capability maturity model integration and web engineering practices in large web development enterprises: An empirical study in Jordan. Journal of Theoretical and Applied Information Technology, 39(2), 150-166.

Bartsch, D. R., Roberts, R. M., Davies, M., \& Proeve, M. (2015). The impact of parental diagnosis of borderline personality disorder on offspring: Learning from clinical practice. Personality and Mental Health, 9(1), 33-43. https://doi.org/10.1002/pmh.1274

Beynon Jr, D. R. (2007). Interpreting capability maturity model integration (CMMI) for business development organizations in the government and industrial business sectors.

Brietzke, J., \& Rabelo, A. (2006). Resistance factors in software process improvement. CLEI electronic journal, 9 , 1.

Butler, K. (1995). The economic benefits of software process improvement. Crosstalk, 8(7), 14-17.

Chopra, S., \& Meindl, P. (2007). Supply chain management. Strategy, planning \& operation. In Das summa summarum des management (pp. 265-275). Gabler.

Chrissis, M. B., Konrad, M., \& Shrum, S. (2003). CMMI guidlines for process integration and product improvement. Addison-Wesley Longman Publishing Co., Inc.

CMMI institute An Isaca Enterprise. (2018). How many organizations have adopted CMMI?[Website]. Retrieved from https://cmmiinstitute.zendesk.com/hc/en-us/articles/216333978-How-many-organizations-have-adopted-C MMI-

Conradi, H., \& Fuggetta, A. (2002). Improving software process improvement. IEEE software, 19(4), 92-99. https://doi.org/10.1109/MS.2002.1020295

Dybå, T. (2003, September). Factors of software process improvement success in small and large organizations: an empirical study in the scandinavian context. In ACM SIGSOFT Software Engineering Notes, 28(5), 148-157. ACM. https://doi.org/10.1145/940071.940092

El Emam, K., \& Koru, A. G. (2008). A replicated survey of IT software project failures. IEEE software, 25(5). https://doi.org/10.1109/MS.2008.107

Farrell, Susan. (May 22, 2016). Open-Ended vs. Closed-Ended Questions in User Research [Website]. Retrieved from https://www.nngroup.com/articles/open-ended-questions/

Goldenson, D. R., \& Herbsleb, J. D. (1995). After the Appraisal: A Systematic Survey of Process Improvement, its Benefits, and Factors that Influence Success (No. CMU/SEI-95-TR-009). CARNEGIE-MELLON UNIV PITTSBURGH PA SOFTWARE ENGINEERING INST.

Horvat, R. V., Rozman, I., \& Györkös, J. (2000). Managing the complexity of SPI in small companies. Software 
Process: $\quad$ Improvement $\quad$ and $\quad$ Practice, $\quad$ 5(1), https://doi.org/10.1002/(SICI)1099-1670(200003)5:1<45::AID-SPIP110>3.0.CO;2-2

Ifinedo, P. (2011). An empirical analysis of factors influencing Internet/e-business technologies adoption by SMEs in Canada. International Journal of Information Technology \& Decision Making, 10(04), 731-766. https://doi.org/10.1142/S0219622011004543

Khan, A. A., \& Keung, J. (2016). Systematic review of success factors and barriers for software process improvement in global software development. IET Software, 10(5), 125-135. https://doi.org/10.1049/iet-sen.2015.0038

Khan, A. A., Keung, J., Niazi, M., Hussain, S., \& Ahmad, A. (2017). Systematic literature review and empirical investigation of barriers to process improvement in global software development: Client-vendor perspective. Information and Software Technology, 87, 180-205. https://doi.org/10.1016/j.infsof.2017.03.006

Khan, A. W., \& Khan, S. U. (2013). Critical success factors for offshore software outsourcing contract management from vendors' perspective: an exploratory study using a systematic literature review. IET software, 7(6), 327-338. https://doi.org/10.1049/iet-sen.2013.0013

Khan, S. U., Niazi, M., \& Ahmad, R. (2009, July). Critical success factors for offshore software development outsourcing vendors: A systematic literature review. In Global Software Engineering, 2009. ICGSE 2009. Fourth IEEE International Conference on (pp. 207-216). IEEE.

Khandelwal, V. K., \& Ferguson, J. R. (1999, January). Critical success factors (CSFs) and the growth of IT in selected geographic regions. In Systems Sciences, 1999. HICSS-32. Proceedings of the 32nd Annual Hawaii International Conference on (pp. 13-pp). IEEE. https://doi.org/10.1109/HICSS.1999.772760

Kishore, R., Swinarski, M. E., Jackson, E., \& Rao, H. R. (2012). A quality-distinction model of IT capabilities: conceptualization and two-stage empirical validation using CMMi processes. IEEE Transactions on Engineering Management, 59(3), 457-469.

Kouzari, E., Gerogiannis, V. C., Stamelos, I., \& Kakarontzas, G. (2015, July). Critical success factors and barriers for lightweight software process improvement in agile development: A literature review. In Software Technologies (ICSOFT), 2015 10th International Joint Conference on (Vol. 1, pp. 1-9). IEEE.

Magdaleno, A. M., Werner, C. M. L., \& De Araujo, R. M. (2012). Reconciling software development models: A quasi-systematic review. Journal of Systems and Software, 85(2), 351-369. https://doi.org/10.1016/j.jss.2011.08.028

Nath, Sheela. (2016, August). Building Capability with CMMI [Web Log]. Retrieved from http://www.isaca.org/KnowledgeCenter/Blog/Lists/Posts/Post.aspx?ID=667\&utm_referrer=direct $\% 2$ Fnot $\%$ 20 provided\&utm_referrer $=$ direct $\% 2$ Fnot $\% 20$ provided $\&$ utm_referrer $=$

Niazi, M. (2009). Software process improvement implementation: avoiding critical barriers. CROSSTALK. The Journal of Defense Software Engineering, 22(1), 24-27.

Niazi, M. (2015). A comparative study of software process improvement implementation success factors. Journal of Software: Evolution and Process, 27(9), 700-722. https://doi.org/10.1002/smr.1704

Niazi, M., Babar, M. A., \& Verner, J. M. (2010). Software Process Improvement barriers: A cross-cultural comparison. Information and software technology, 52(11), 1204-1216. https://doi.org/10.1016/j.infsof.2010.06.005

Niazi, M., Wilson, D., \& Zowghi, D. (2006). Critical success factors for software process improvement implementation: an empirical study. Software Process: Improvement and Practice, 11(2), 193-211. https://doi.org/10.1002/spip.261

O'Connor, R. V., \& Coleman, G. (2007). An investigation of barriers to the adoption of software process best practice models.

Oxford Business Group. (2015). Jordan National Information and Communications Technology Strategy [Overview]. $\quad$ Retrieved from https:/oxfordbusinessgroup.com/overview/dynamic-market-private-sector-ambitions-rising-internet-penetra tion-and-shift-4g-are-tran-0

Pitterman, B. (2000). Telcordia technologies: the journey to high maturity. IEEE Software (July-August), 89-96.

Pusatli, O. T., \& Misra, S. (2011). A discussion on assuring software quality in small and medium software 
enterprises: An empirical investigation. Technical Gazette, 18(3), 447-452.

Rainer, A., \& Hall, T. (2002). Key success factors for implementing software process improvement: A maturity-based analysis. Journal of Systems and Software, 62(2), 71-84. https://doi.org/10.1016/S0164-1212(01)00122-4

Ramasubbu, N. (2014). Governing software process improvementsin globally distributed product development. IEEE Transactions on Software Engineering, 40(3), 235-250. https://doi.org/10.1109/TSE.2013.58

SEI, S. (2010). CMMI ${ }^{\circledR}$ for development, version 1.3, Improving processes for developing better products and services. No. CMU/SEI-2010-TR-033. Software Engineering Institute Google Scholar.

Silva, F. S., Soares, F. S. F., Peres, A. L., de Azevedo, I. M., Vasconcelos, A. P. L., Kamei, F. K., \& de Lemos Meira, S. R. (2015). Using CMMI together with agile software development: A systematic review. Information and Software Technology, 58, 20-43. https://doi.org/10.1016/j.infsof.2014.09.012

Sommerville, I. (2010). Software engineering. New York: Addison-Wesley.

Staples, M., \& Niazi, M. (2008). Systematic review of organizational motivations for adopting CMM-based SPI. Information and software technology, 50(7-8), 605-620. https://doi.org/10.1016/j.infsof.2007.07.003

Staples, M., Niazi, M., Jeffery, R., Abrahams, A., Byatt, P., \& Murphy, R. (2007). An exploratory study of why organizations do not adopt CMMI. Journal of systems and software, 80(6), 883-895. https://doi.org/10.1016/j.jss.2006.09.008

Sulayman, M., Mendes, E., Urquhart, C., Riaz, M., \& Tempero, E. (2014). Towards a theoretical framework of SPI success factors for small and medium web companies. Information and Software Technology, 56(7), 807-820. https://doi.org/10.1016/j.infsof.2014.02.006

Villalón, J. A. C. M., Agustín, G. C., Gilabert, T. S. F., Seco, A. D. A., Sánchez, L. G., \& Cota, M. P. (2002). Experiences in the application of software process improvement in SMES. Software Quality Journal, 10(3), 261-273. https://doi.org/10.1023/A:1021638523413

Villalon, J. A. C. M., Cuevas Agustin, G., San Feliu Gilabert, T., Serrano Rico, A. E., \& García Pacheco, I. (2006). A software process improvement solution for small and medium-size enterprises.

Wang, Y. M., Wang, Y. S., \& Yang, Y. F. (2010). Understanding the determinants of RFID adoption in the manufacturing industry. Technological forecasting and social change, 77(5), 803-815. https://doi.org/10.1016/j.techfore.2010.03.006

Wongsai, N., Siddoo, V., \& Wetprasit, R. (2015, October). Factors of influence in software process improvement: An ISO/IEC 29110 for very-small entities. In Information Technology and Electrical Engineering (ICITEE), 2015 7th International Conference on (pp. 12-17). IEEE. https://doi.org/10.1109/ICITEED.2015.7408904

Yamamura, G. (1999). Software process satisfied employees. IEEE Software, 16(5), 83-85.

Zhu, K., Kraemer, K., \& Xu, S. (2003). Electronic business adoption by European firms: A cross-country assessment of the facilitators and inhibitors. European Journal of Information Systems, 12(4), 251-268. https://doi.org/10.1057/palgrave.ejis.3000475

\section{Note}

Note 1. "An alternative software process improvement method for small- and medium-size enterprises based on the action package concept" (Villalon et al. 2006).

\section{Copyrights}

Copyright for this article is retained by the author(s), with first publication rights granted to the journal.

This is an open-access article distributed under the terms and conditions of the Creative Commons Attribution license (http://creativecommons.org/licenses/by/4.0/). 